\title{
Progress and Future Directions in Computational Fluid Dynamics
}

Paul Kutler and Anthony R. Gross

June 1988 


\section{Progress and Future Directions in Computational Fluid Dynamics}

Paul Kutler

Anthony R. Gross, Ames Research Center, Moffett Field, California

June 1988

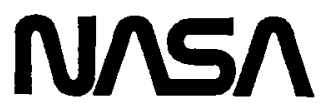

National Aeronautics and

Space Administration 


\title{
PROGRESS AND FUTURE DIRECTIONS IN
}

\section{COMPUTATIONAL FLUID DYNAMICS}

\author{
Paul Kutler* and Anthony R. Gross $\dagger$ \\ Ames Research Center
}

\section{SUMMARY}

Computational fluid dynamics (CFD) has made great strides in the detailed simulation of complex fluid flows, including the fluid physics of flows heretofore not understood. It is now being routinely applied to some rather complicated problems, and starting to impact the design cycle of aerospace flight vehicles and their components. In addition, it is being used to complement and is being complemented by experimental studies. In the present paper, some major elements of contemporary CFD research, such as code validation, turbulence physics, and hypersonic flows are discussed, along with a review of the principal pacing items that currently govern CFD. Several examples are presented to illustrate the current state of the art. Finally, prospects for the future of the development and application of CFD are suggested.

\section{INTRODUCTION}

Fifteen years ago the discipline of computational fluid dynamics (CFD) moved into its modern phase and began to demonstrate the potential that is today being realized. The facets that compose the discipline of CFD, such as algorithm development, grid generation, geometry definition, boundary and initial conditions, turbulence modeling, pre- and post-data processing, computer technology, and so on, were all ripe for technological advances. Because of the demonstrated potential of CFD and the understood limitations of experimental testing, the discipline of CFD developed at a rapid pace. As a result, CFD applications have evolved with three major objectives. The first of these is to understand the fundamental processes of fluid physics, including such elements as viscous fluid flows and turbulence, vortical flows, and component interaction effects.

The second major objective is to complement experimental studies, (i.e., aid in the design of experiments) including models and instrument placement, correct measurements for laboratory-induced effects, extend results beyond the range of experiment, and aid in the interpretation of the resulting measurements. In addition, CFD can provide information not otherwise accessible; i.e., to simulate phenomena not reproducible in the laboratory, or to obtain relationships between variables not possible to measure, or to solve governing equations too complex to treat analytically.

The third major objective is, in part, a synthesis of the previous two. It is to aid in the development of improved and advanced aerospace vehicles and their components. With the geometrical flexibility inherent in the CFD process, many different designs can be relatively easily and quickly analyzed and component development and interaction problems become much more tractable. As will be shown in the following sections, great progress has been made toward achieving these objectives, although much remains to be done.

\footnotetext{
${ }^{*}$ Chief, Fluid Dynamics Branch.

$\dagger$ Deputy Chief, Fluid Dynamics Branch.
} 


\section{NEW CFD ELEMENTS}

In recent times four new elements have evolved in the process of CFD applications, each one representing a major direction of CFD research and development. The first of these new elements is code validation. Although CFDers have been comparing computed results with experimental measurements, or other codes, as available, there is now a concerted effort to develop experiments especially designed to validate modern, complex CFD codes. These new experiments uses the latest optical instrumentation to obtain accurate, high-resolution-field measurements to compare with computed values. By this process CFD will develop the level of confidence that will permit its continued widespread adoption by the aerospace industry. In this context, CFD has spawned a renaissance in experimental research and instrument development.

The second modern CFD element is hypersonic flows. With the advent of the National Aerospace Plane (NASP) program, hypersonic flows have become a major area of CFD research and development. One of the key elements of this program is the recognition that a substantial portion of the design of such a vehicle will have to be accomplished by CFD, since ground test facilities do not exist for such speeds and energy levels inherent in flight at Mach numbers of up to 25, and there is not the database of technology and experience that is available for more conventional aircraft. Hypersonic flows present a number of new and difficult challenges to simulation by CFD, foremost among them being the necessity of including the effects of real-gas chemistry in the numerical solution. Other difficult aspects associated with hypersonic flows include compressibility effects in turbulence modeling, boundary-layer transitional effects, and the importance and sensitivity of heat transfer calculations,. In addition, the strength of the shock and its proximity to the boundary layer in the vicinity of the nose leads to problems of computational stability and nonlinearity not found in flows at lower speeds.

A third element is the concentration of resources in the numerical simulation of the physics of turbulence. Turbulence and its mechanisms represent the single most difficult factor in the development of CFD as a complete fluid flow analysis tool. The simulation of viscous flows is being attacked from both ends of the computational spectrum. At one end are the scientists that solve the Reynolds averaged Navier-Stokes (RANS) equations, with a suitable turbulence model derived from theoretical analysis and data obtained from experiments. At the other end of the spectrum are the scientists that solve the complete Navier-Stokes equations, with either a subgrid model for the small scales of turbulence (large eddy simulation) or no model at all (direct simulation). As time progresses and CFD and computer technology mature, it is hoped that the two approaches will merge. As the direct numerical simulations progress, it is becoming possible to use the numerical data generated from those solutions to create new turbulence models. Such data provides much more information than can be gleaned from an experiment, thus permitting the construction of better turbulence models. The limitation, of course, is with the geometrically simplified and low Reynolds

The fourth element of contemporary CFD technology is that of scientific visualization; i.e., the use of advanced workstations to both display and analyze numerical flow simulations. The complexity of the grid systems associated with modern aerospace vehicles geometries, as well as the magnitude of the numerical results, require special visualization and analysis tools to permit the scientist to both develop and effectively comprehend the many facets of the solution. In addition, by using the workstation to interactively couple the scientist and the computer, the scientist will gain a faster and more complete understanding of the results, as well as facilitating the transfer of his results and technology to other scientists.

The next section will present a few examples and results to illustrate these elements and to indicate current problems. 


\section{EXAMPLES AND RESULTS}

The first example, that of high angle-of-attack aerodynamics, is one that is both extending our knowledge of fluid flow process and serving to validate a computer code. Modem aircraft, with their characteristically long, slender nose shapes, and operation at high angles of attack, develop unusual flow patterns and forces, with the result that their controllability is frequently affected. Considerable research is being aimed at understanding these complex and important flow fields. The results of a joint computational-experimental study of such a vortical flow field on an ogive cylinder is shown in figure 1 . The incompressible Navier-Stokes equations were solved for the steady flow at $45^{\circ}$ angle of attack, while the experimental data were obtained in both a wind tunnel and a towing tank. The complexity of the flow is clearly apparent, as is the generally good agreement between the computational and experimental results. Further details are given in reference 1.

The computation of the the time-dependent flow over the integrated Space Shuttle launch configuration is a good example of a contemporary CFD simulation problem (ref. 2). In this case, the numerical simulation is being used to analyze flight performance, and the feasibility of crew escape during launch. A solution was developed by solving the three-dimensional Reynolds-averaged unsteady Navier-Stokes equations using a composite grid and an algebraic turbulence model. A comparison of computed and experimental results are shown in figure 2. Although the support structure between the orbiter and the external tank was not modeled, the computed results compare well with the experimental values. Future work will extend the simulation to include staging, where the orbiter will separate from the Solid Rocket Booster and External Tank assembly.

A major new thrust of CFD research is to develop the capability to compute the real-gas aerothermodynamic characteristics of hypersonic vehicles and to use that capability to guide the design of such vehicles. The external aerodynamics of a NASP-like configuration is shown in figure 3 . These results were computed by solving the three-dimensional Reynolds-averaged Navier-Stokes equations in parabolized form using algebraic turbulence models, with perfect gas approximations. Research is currently progressing toward developing both equilibrium and nonequilibrium (finite-rate chemistry) real gas flow simulations.

One of the critical elements of hypersonic flight is the propulsion system, and its integration into the airframe. The intersection of the bow shock with the lip of the inlet cowl is a complex shock system that changes considerably with small changes in flow conditions and angle of attack. The results of a numerical simulation of the viscous hypersonic shock-shock interaction with the blunt cowl lip are shown in figure 4. Six separate types of interaction are identified as the bow shock sweeps over the cowl lip. These results were developed using the Navier-Stokes equations with a TVD scheme (ref. 3). Results have shown that peak heating can exceed that from stagnation conditions alone by up to a factor of two, attributed to the complex shock interactions.

In recent years considerable progress has been made in the numerical simulation of the physics of turbulence. Using the compete, time-dependent Navier-Stokes equations without modeling, along with a high-capacity workstation, it is now possible to view the development and propagation of turbulence quantities (ref. 4). Such a result is shown in figure 5 , which represents the structure of turbulence in a simulated flat-plate boundary layer. There were 9.4 million grid points used for this computation. In the figure, the elongated white surfaces identify the low-pressure vortex cores. The red and blue areas identify where significant contributions to the Reynolds shear stress are occurring, with the red indicating regions of low-speed fluid being ejected outwards, and the blue denoting regions of high-speed fluid is being

swept towards the wall. These kinds of presentations help the scientist to more clearly understand the role that each of the physical variables play in the onset of fluid turbulence, and can significantly aid in the development of statistical models to represent such turbulent flows. 
With the advent of modern V/STOL aircraft, such as the British Harrier, a great deal of interest has been generated in the fluid dynamics of powered lift. To study the fundamental mechanisms of such flows, the effects of a jet in a cross flow were studied numerically by using a Navier-Stokes simulation (ref. 5). The results for a selected flow condition are shown in figure 6. Using a high-resolution workstation it is possible to visualize the otherwise complex flow field in great detail.

Finally, an example is presented to illustrate the application of CFD to the problem of designing and interpreting an experiment. To both validate a major CFD code and investigate the flow about a modern fighter-type wing-body combination, three separate CFD codes were used. First, a panel methods code was used to evaluate the potential effects of wind tunnel wall interence, predict the onset of supercritical flow, and develop an evaluation of subsonic model loads. Second, an axisymmetric transonic full potential code was used to redesign the nose of the body to eliminate body-tunnel shock interference and to specify the location of pressure taps to resolve the body flow field. Third, a transonic full potential wing code was employed to insure the presence of supercritical flow on the wing for the Mach numbers to be investigated, to guide the placement of pressure taps to resolve the wing flow field, and to predict the transonic model loads. The model is shown in figure 7. Experimental results, and comparisons with numerical simulations, for the wing alone are presented in figure 8. The experiment was designed to develop data to validate the NASA Ames Research Center TNS Code, a three-dimensional, zonal, Reynolds-averaged Navier-Stokes code that will be used for the analysis of complex configurations. Future experimental work will include testing the complete wing-body configuration, as well as grid refinement studies to evaluate the effects of

\section{PACING ELEMENTS}

In 1981 the pacing items for CFD included three-dimensional grid generation, turbulence modeling, algorithm development, and computer mainframe design advances (ref. 6). In 1983 the list was expanded to include primary and secondary pacing items (ref.7). The primary items included grid generation, turbulence modeling, computer power, and solution methodologies; the secondary items included algorithm development, complex geometry definition, and pre- and post-data processing. In this section, pacing items of the past are reviewed and updated, and major accomplishments are summarized.

The continued demand for more powerful computers by computational fluid dynamicists to perform not only direct Navier-Stokes simulations for simple geometries, but Reynolds-averaged Navier-Stokes calculations for complex three-dimensional configurations continues to pace the progress of CFD. In addition, problems such as hypersonics that require the solution of not only the Navier-Stokes equations but also the finite-rate chemistry equations, will require computers orders of magnitude faster than those currently available.

The process of grid generation has received considerable attention by scientists because of the need to efficiently and effectively distribute grid points to generate the most accurate flow solution possible. To date, very complicated configurations have been treated computationally. Slightly different grid topologies have been used to discretize the flow about the Space Shuttle orbiter (a single module grid) and a generic aircraft configuration (a multiple module or block grid). The grid for the Space Shuttle orbiter used a hyperbolic solver while the grid for the aircraft employed an elliptic solver.

Two noteworthy solution methods that have resulted in advancements in the state of the art in CFD include a zonal procedure for treating a rotor-stator combination; i.e., a multiple moving body problem, and a tetrahedron procedure for treating commercial aircraft configurations. The zonal procedure is applicable for moving bodies and required the development of boundary condition procedures for transmitting information from one moving grid to the other. The tetrahedron procedure permits easy treatment of complicated configurations because the flow region of interest is discretized using tetrahedrons. It required the 
development of a boundary condition procedure for conserving fluxes across the surfaces of the volumes that did not degrade the accuracy of the solution. In addition, a data management system for handling the randomly placed control volumes was developed.

\section{DIRECTIONS FOR THE FUTURE}

A considerable number of challenging technical areas exist for which CFD will be beneficial and sometimes mandatory. Two areas of particular importance that will be addressed are unsteady flows and interdisciplinary physics.

The simulation of unsteady viscous flows about realistic aircraft configurations is now possible using computational tools. Several computer codes for simulating these flows have been developed by various researchers around the country. With these codes, it will now be possible to begin studying unsteady flow problems that result when high performance aircraft fly at large angles of attack. These unsteady flows include asymmetric vortex shedding and vortex breakdown or bursting. Thus, it will be possible to use these codes for predicting aircraft performance near their performance boundaries.

Interdisciplinary physics will not only offer significant challenges to the research scientist, but also challenge the power of existing or planned computational facilities. The mating of different technical disciplines into one computer program for more relevant design applications will tax both scientist and machine. Typical will be the coupling of the finite-rate chemistry equations with the Navier-Stokes equations. In the past, simple couplings have occurred such as linking a structural response code to a fluid dynamics code to study aeroelastic problems or the coupling of a flow code with an optimization routine for wing design. In the future other disciplines will be linked with these, such as propulsion and controls.

In addition to the CFD elements previously mentioned, new hardware and software developments will play a major role in the advancement of CFD and its applications. Two that will be discussed here are parallel processing and artificial intelligence.

Most of the CFD development to date has taken place on single processor computers. With advances in clock speed and memory size, brought about largely by more efficient chips, the overall processing speed and power has increased by orders of magnitude during the past 10 years. The physical limits of such development are now being approached, caused by inherent electron speeds and problems of cooling (ref. 8). Although new opportunities may be provided by the development of practical means of achieving near-room temperature superconductivity, the direction most likely for the future is parallel processing. Indeed, most of the current crop of supercomputers have more than one processor, up to six in some cases. However, the development of moderate to large-scale parallel processing hardware is a current reality -- the impediment to their rapid application to the problems of CFD is the limited amount of software currently available. How to formulate the equations of CFD suitable for solution on a multi-thousand processor machine, as well as how to manage the data internally among the processors are research problems at the present time. Nevertheless, progress is being made, as at Ames Research Center, the Navier-Stokes equations are being solved on a 16000 processor computer. Great strides remain to be made in this area, but the promise of a new generation of supercomputers, able to handle problems that are now not

Finally, the techniques and potential capabilities of artificial intelligence (AI) are a promising direction for the development of CFD. Expert systems are already being explored to help the CFD scientist divide a complex flow region into several zones, each of which can then be discretized using relatively simple grids. At the other end of the numerical simulation process, visualizing the computed results, AI will be used to investigate and analyze the resulting flow. patterns, and identify those deemed to be of most 
interest. Such tools will provide the aerodynamicist with the means to quickly identify problem areas, speed the solution process, and possibly even suggest alternative configurations.

\section{CONCLUSIONS}

Computers are assuming an increasingly important role in aerospace research and development. Computational fluid dynamics is rapidly becoming an extremely powerful tool in the design process as well as the understanding of complex fluid physics. Substantial payoffs in both arenas have been demonstrated. The validation of CFD codes has been shown to now be a particularly important element of the CFD process, to build the confidence necessary to further extend its practicality. The accurate and rapid simulation of turbulence is the key pacing item in the ultimate application of CFD to problems of aerospace vehicle design and performance prediction. Hypersonic flows, with their necessary coupling of real-gas and flow simulations, is now a major element of the CFD research and development program, and will play a critical role in the design of all future hypersonic flight vehicles. Finally, limitations inherent in serial processing machines will soon be reached, and it will be necessary to explore massively parallel solution methodologies to continue the rapid growth of CFD technology.

\section{REFERENCES}

1. Zilliac, G. G.: A Computational/Experimental Study of the Vortical Flow Field on a Body of Revolution at Angle of Attack. AIAA Paper 87-2277-CP, August, 1987.

2. Buning, P.; Chiu, I.; Obayashi, S.; Rizk, Y.; and Steger, J. L.: Numerical Simulation of the Integrated Space Shuttle Vehicle in Ascent. AIAA Atmospheric Flight Mechanics Meeting, Minneapolis, Minnesota, August, 1988.

3. Klopfer, G. H.; and Yee, H. M. C.: Viscous Hypersonic Shock on Shock Interaction on Blunt Cowl Lips. AIAA Paper 88-0233, Janaury, 1988.

4. Robinson, S. K.; Kline, S. J.; and Spalart, P. R.: Spatial Charater and Time-Evolution of Coherent Structures in a Numerically Simulated Boundary Layer. First National Fluid Dynamics Congress, Cincinnati, Ohio, July, 1988.

5. Van Dalsem, W. R.: Study of Jet in Ground Effect with Crossflow Using the Fortified Navier-Stokes Scheme. AIAA Paper 87-2279-CP, August, 1987

6. Chapman, D. R.: Trends and Pacing Items in Computational Aerodynamics. Lecture Notes in Physics, Vol. 141, edited by W. C. Reynolds and R. W. MacCormack, 1981.

7. Kutler, P.: A Perspective of Theoretical and Applied Computational Fluid Dynamics. AIAA Paper 83-0037, 21st Aerospace Sciences Meeting, Reno, Nevada, January, 1983.

8. Karin, S.; and Smith, N. P.: The.Supercomputer Era, Harcourt Brace Jovanovich, Publishers, N. Y., 1987. 

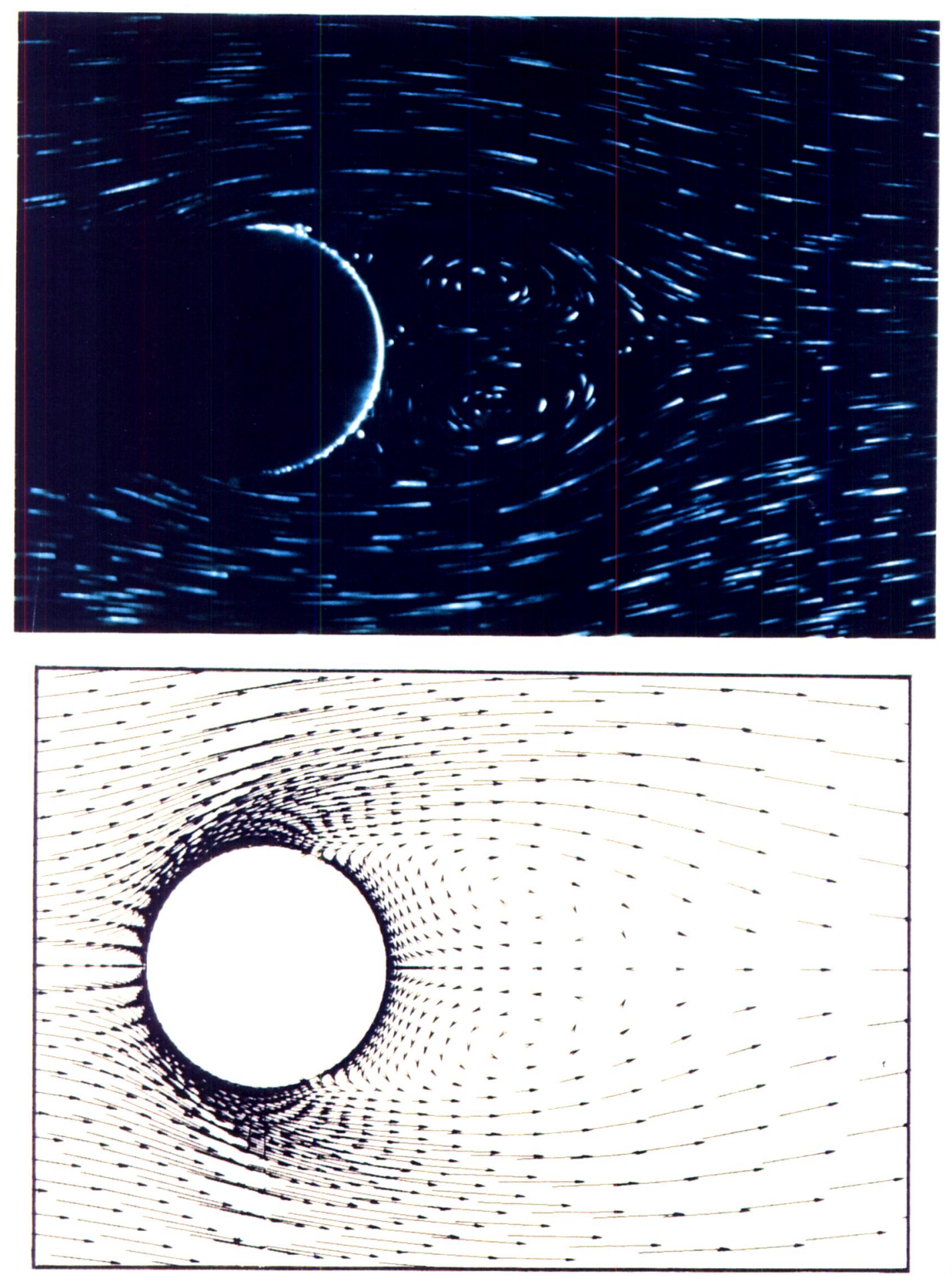

Figure 1.- High angle-of-attack aerodynamics. 


\section{STS ASCENT CONFIGURATION}

\section{COMPARISON OF PRESSURE COEFFICIENT} IA105A Wind Tunnel Test with F3D/Chimera Novier-Stokes Solver
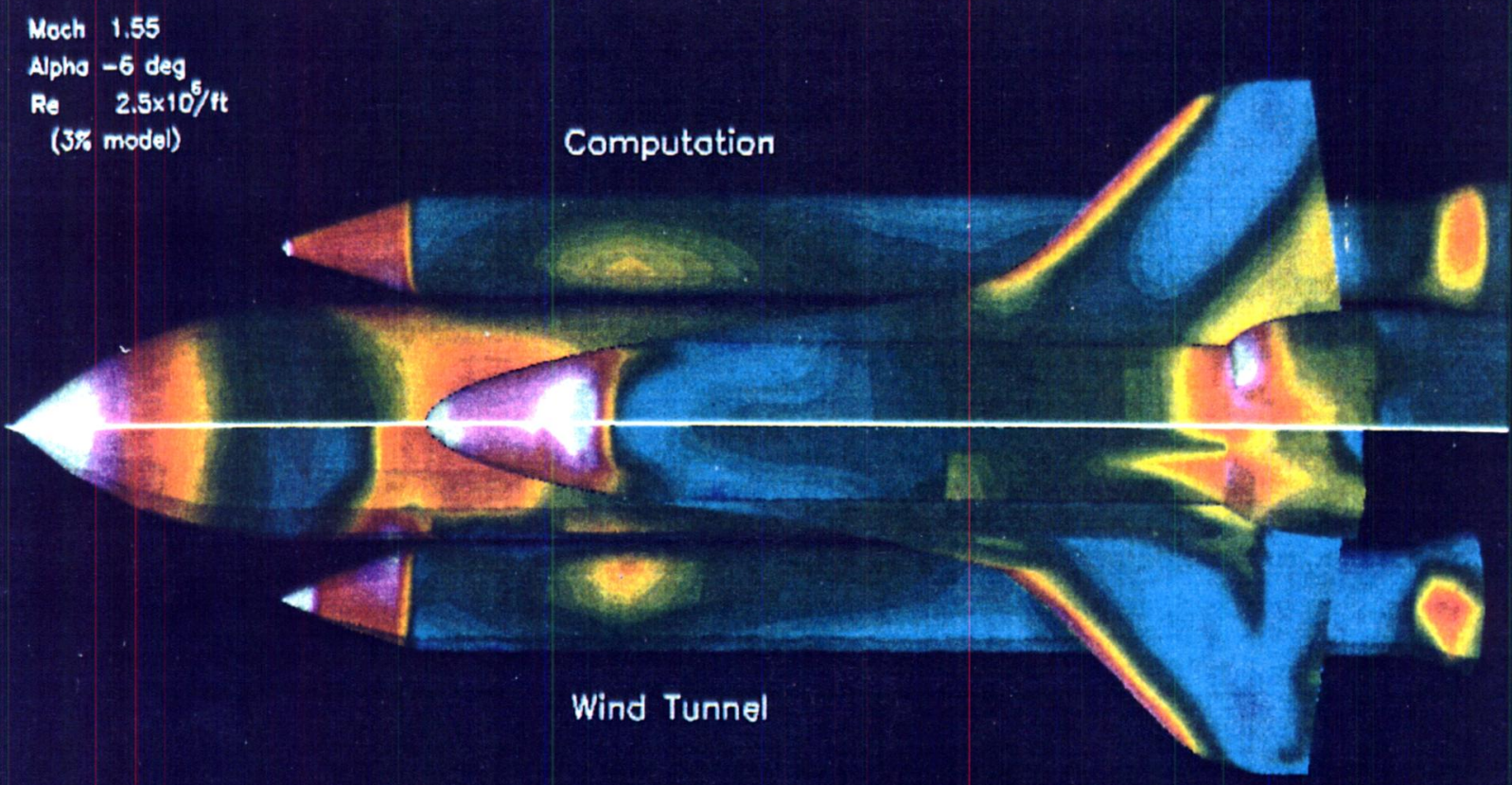


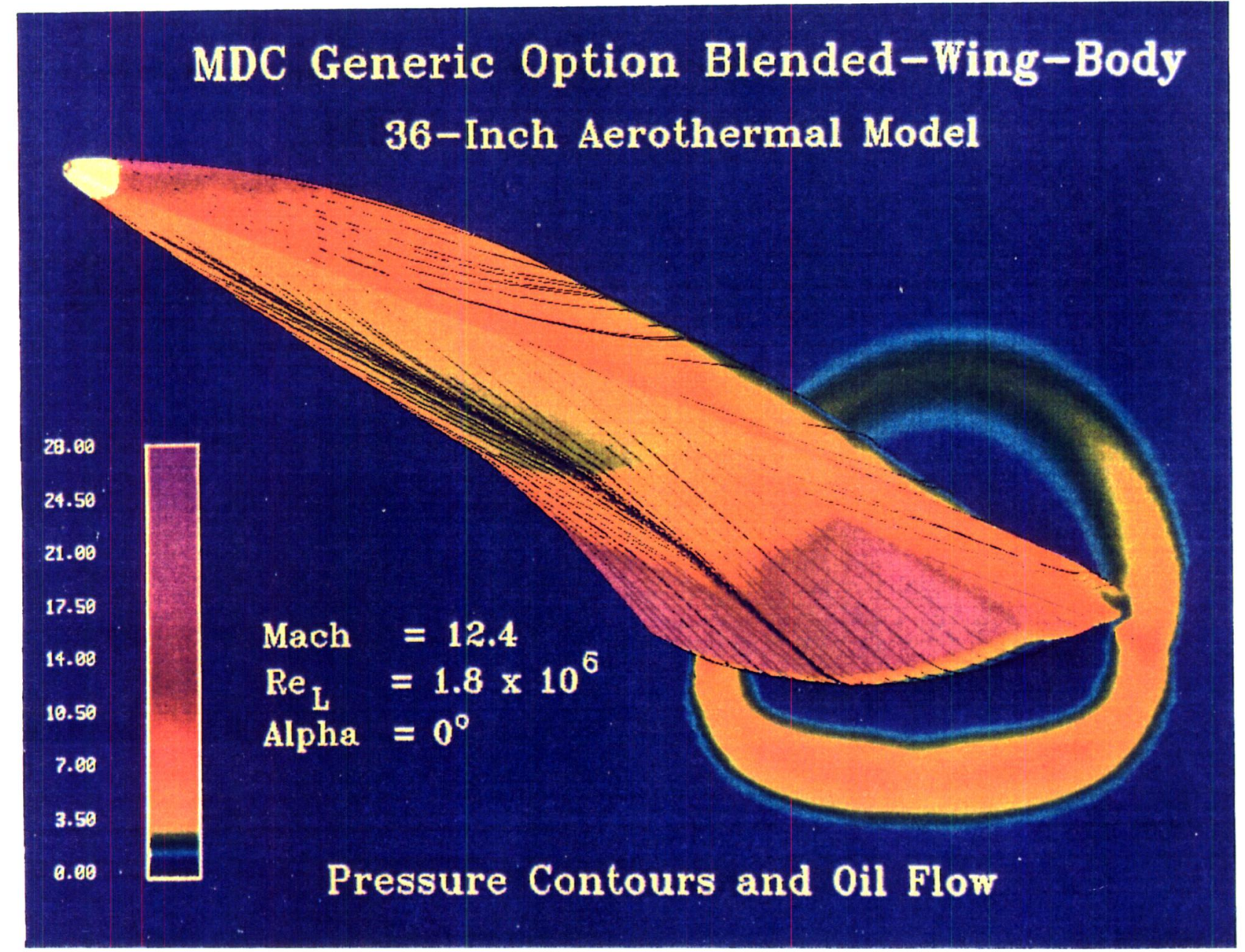

Figure 3.- Ames Research Center's all-body hypersonic vehicle pressure contours. 
TYPICAL OVERALL FLOW FIELD
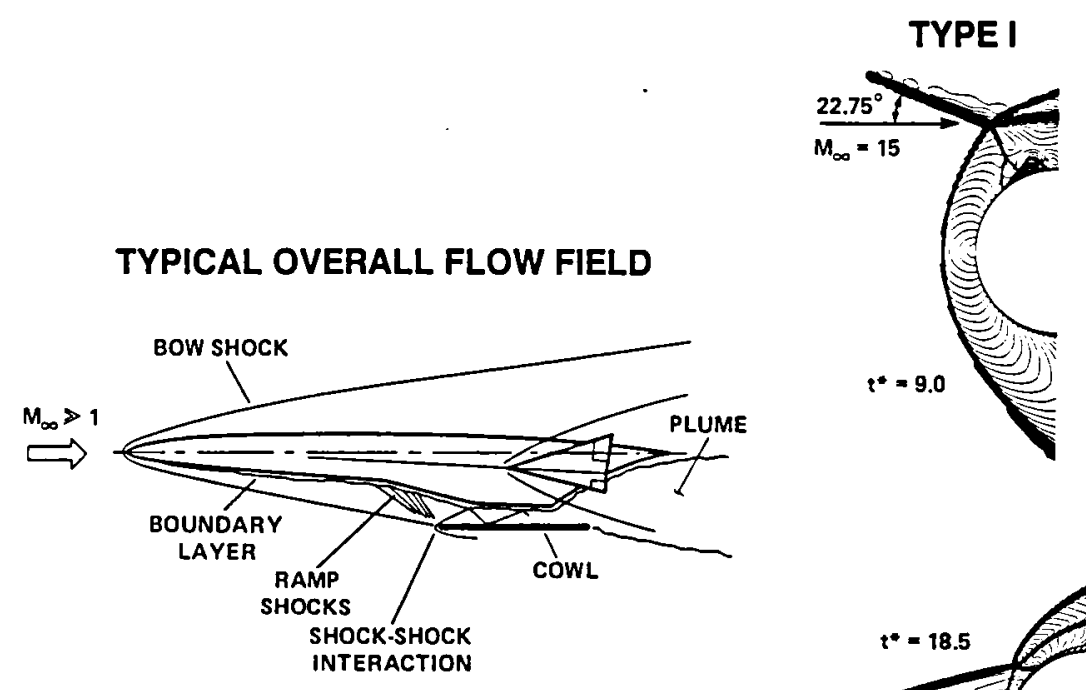

TYPE II

TYPE $\|^{+}$
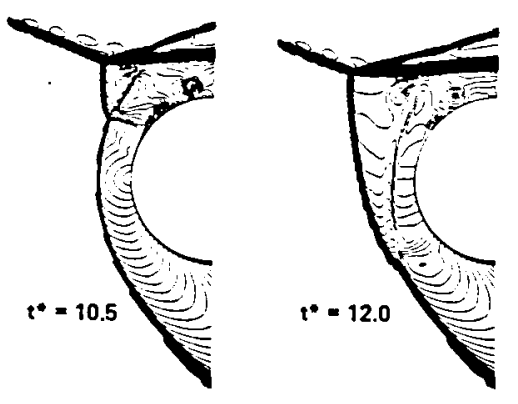

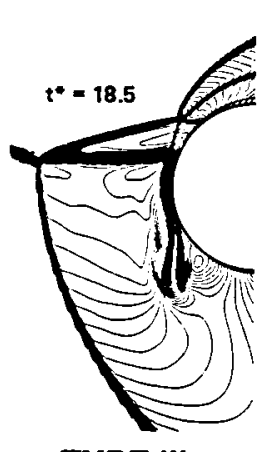

TYPE III

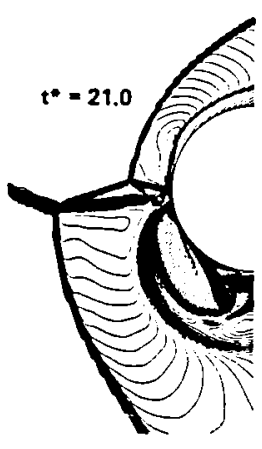

TYPE IV

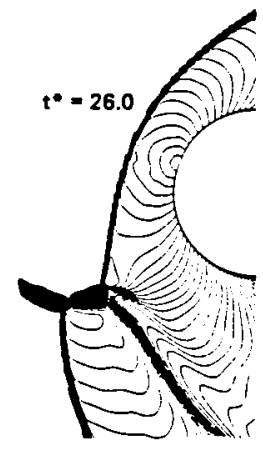

TYPE V

Figure 4.- Viscous hypersonic shock on shock iteration with a blunt cowl lip. 


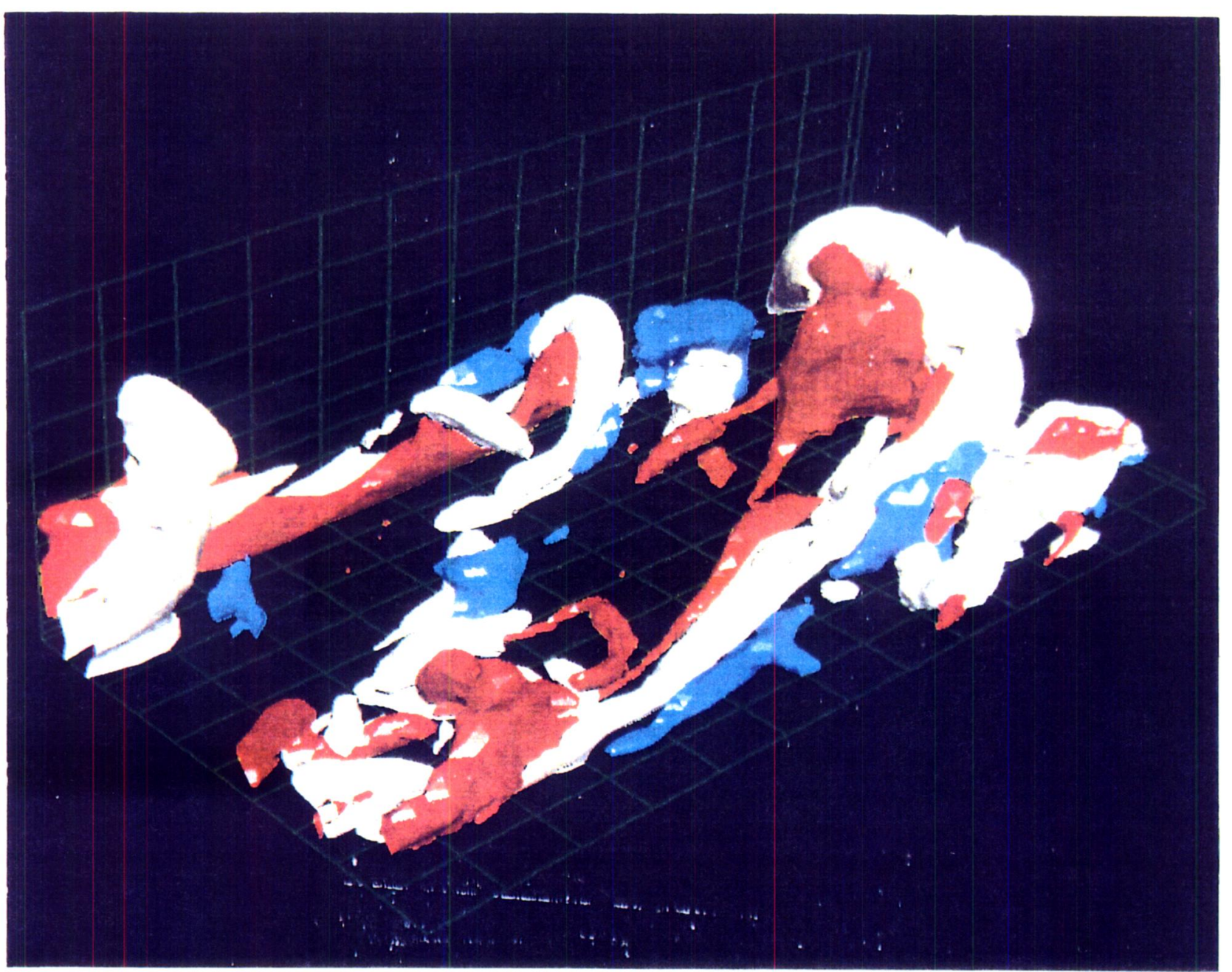

Figure 5.- Turbulence physics. 


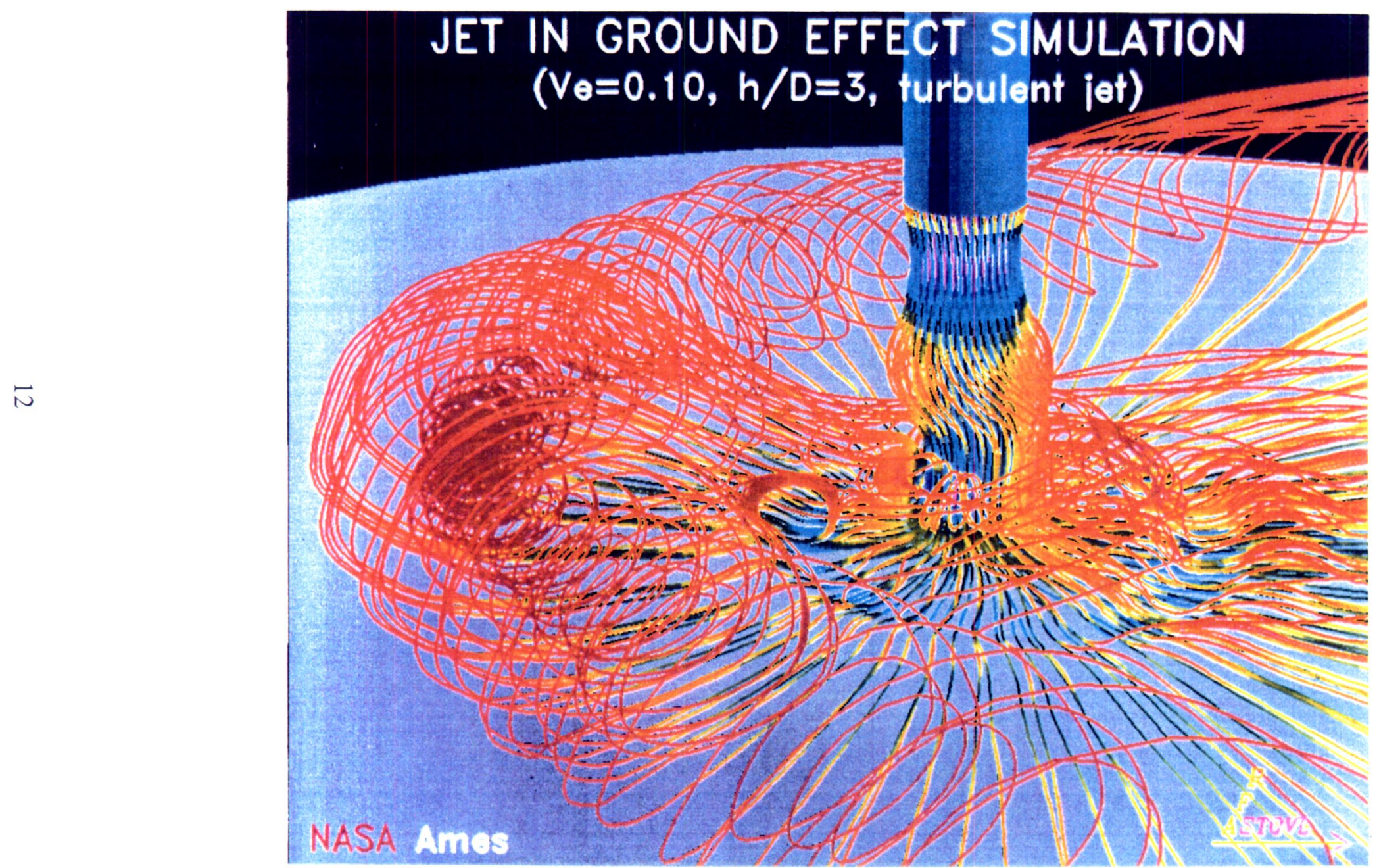

Figure 6.- Iteration of a jet in a crossflow. 

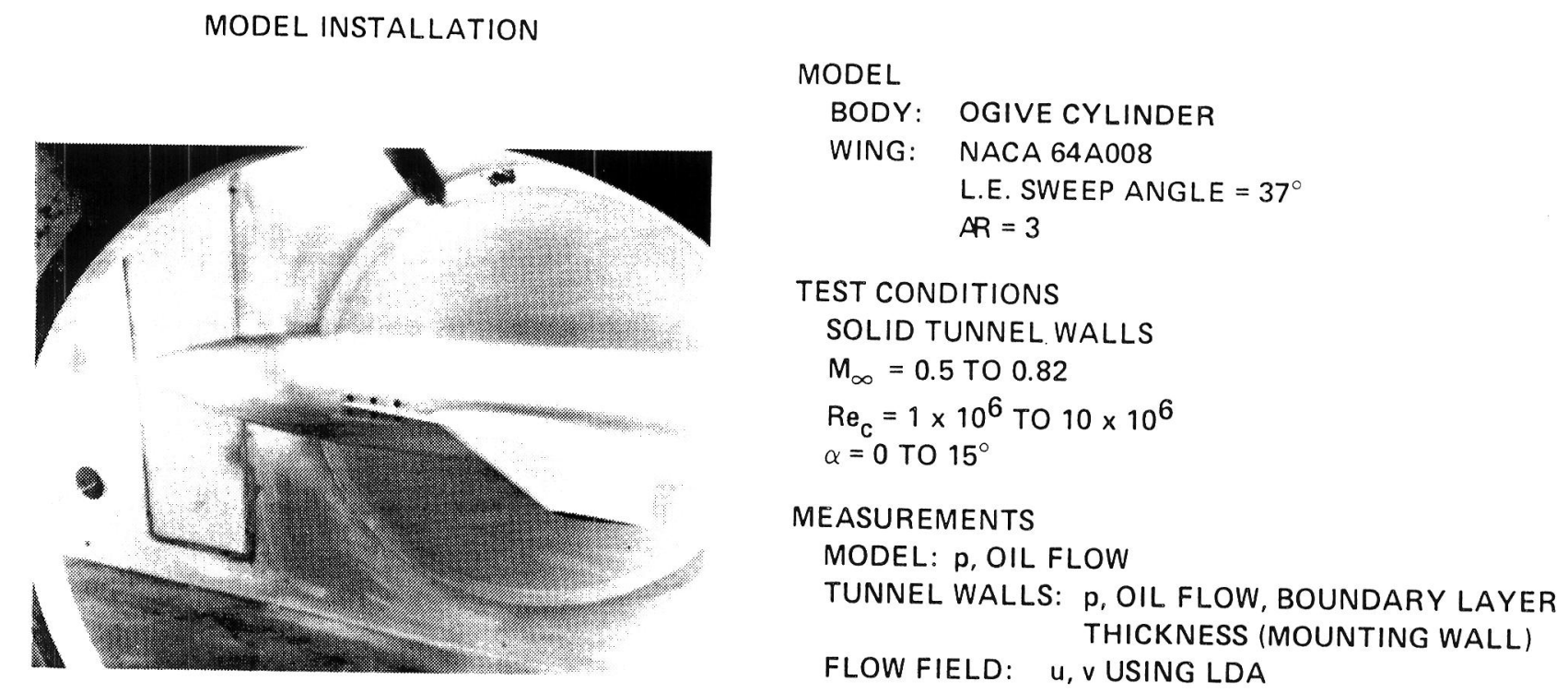

Figure 7.- Wing-body model in Ames Research Center wind tunnel. 
Experiment $30 \%$ span

TNS, 27\% span (poor grid)

- TWING 28.57\% span (find $\mathrm{g}^{\mathrm{i}} \mathrm{d}$ )

-... TWIN̄ $32.65 \%$ span (rind grid)

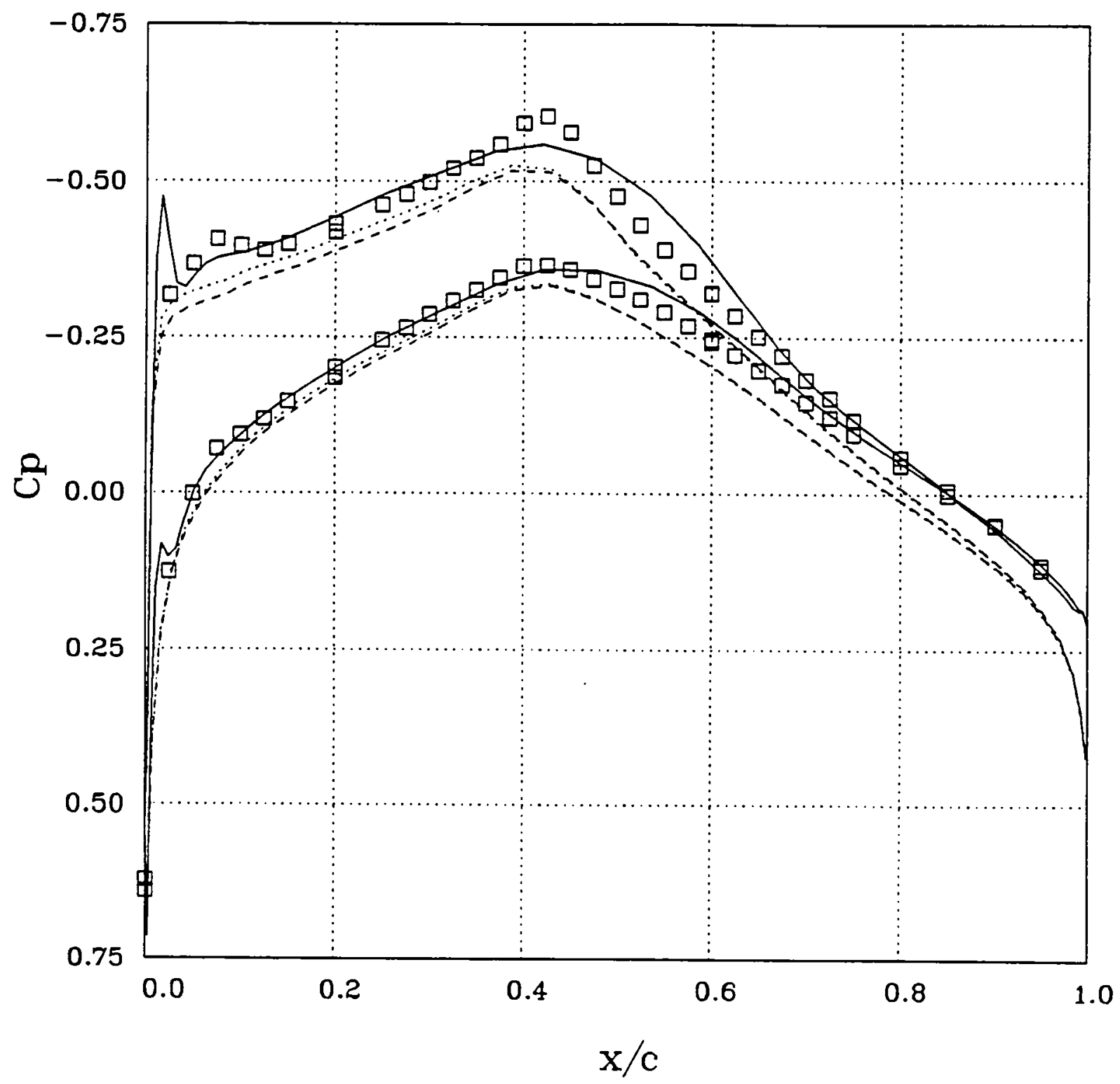

Figure 8.- Low-aspect-ratio wing test results. 


\begin{tabular}{|c|c|c|}
\hline Nush & \multicolumn{2}{|c|}{ Report Documentation Page } \\
\hline $\begin{array}{l}\text { 1. Report No. } \\
\text { NASA TM } 100091\end{array}$ & 2. Government Accession No. & 3. Recipient's Catalog No. \\
\hline \multirow{2}{*}{\multicolumn{2}{|c|}{$\begin{array}{l}\text { 4. Title and Subtitle } \\
\text { Progress and Future Directions in Computational } \\
\text { Fluid Dynamics }\end{array}$}} & $\begin{array}{l}\text { 5. Report Date } \\
\text { June } 1988\end{array}$ \\
\hline & & 6. Performing Organization Code \\
\hline \multirow{2}{*}{\multicolumn{2}{|c|}{$\begin{array}{l}\text { 7. Author(s) } \\
\text { Paul Kutler and Anthony R. Gross }\end{array}$}} & $\begin{array}{l}\text { 8. Performing Organization Report No. } \\
\text { A-88128 }\end{array}$ \\
\hline & & 10. Work Unit No. \\
\hline \multicolumn{2}{|c|}{ 9. Performing Organization Name and Address } & $505-60-01$ \\
\hline \multirow{2}{*}{\multicolumn{2}{|c|}{$\begin{array}{l}\text { Ames Research Center } \\
\text { Moffett Field, CA } 94035\end{array}$}} & 11. Contract or Grant No. \\
\hline & & 13. Type of Report and Period Covered \\
\hline \multirow{2}{*}{\multicolumn{2}{|c|}{$\begin{array}{l}\text { 12. Sponsoring Agency Name and Address } \\
\text { National Aeronautics and Space Administration } \\
\text { Washington, DC 20546-0001 }\end{array}$}} & Technical Memorandum \\
\hline & & 14. Sponsoring Agency Code \\
\hline
\end{tabular}

15. Supplementary Notes

Point of Contact: Anthony R. Gross, MS 258-3, Ames Research Center, Moffett Field, CA 94035 (415) 694-4005 or FTS 464-4005

16. Abstract

Computational fluid dynamics (CFD) has made great strides in the detailed simulation of complex fluid flows, including the fluid physics of flows heretofore not understood. It is now being routinely applied to some rather complicated problems, and starting to impact the design cycle of aerospace flight vehicles and their components. In addition, it is being used to complement and is being complemented by experimental studies. In the present paper, some major elements of contemporary CFD research, such as code validation, turbulence physics, and hypersonic flows are discussed, along with a review of the principal pacing items that currently govern CFD. Several examples are presented to illustrate the current state of the art. Finally, prospects for the future of the development and application of CFD are suggested.

17. Key Words (Suggested by Author(s))

Turbulence, Aerodynamics Hypersonics, Space Shuttle Computational fluid dynamics
18. Distribution Statement

Unclassified - Unlimited

Subject Category: 01
19. Security Classif. (of this report) Unclassified
20. Security Classif. (of this page) Unclassified
21. No. of pages

15
22. Price

A02 